\title{
Clinical study and management of congenital inguinal hernia in a tertiary care teaching institute
}

\author{
Singh N. ${ }^{1}$, Rohit D. K. ${ }^{2}$, Verma R.S. ${ }^{3}$, Pandey G. ${ }^{4}$ \\ ${ }^{1}$ Dr. Nagendra Singh, Associate Professor, ${ }^{2}$ Dr. Dushyant Kumar Rohit, Associate Professor, ${ }^{3}$ Dr. R. S. Verma, Professor, \\ ${ }^{4}$ Dr. Grishmraj Pandey, Intern, all authors are affiliated with Department of Surgery, Bundelkhand Medical College, \\ Sagar, Madhya Pradesh, India.
}

Corresponding Author: Dr. Dushyant Kumar Rohit, Address: F-2, Balak Hill View Colony, Shivaji Ward, Tilli, Sagar, Madhya Pradesh.E-mail: rythmmakers@gmail.com

\begin{abstract}
Background: Inguinal hernia in children is a quite common presentation and inguinal herniotomy is a frequently done procedure in children for inguinal hernia. Inguinal hernia has a higher familiar incidence and it has been observed with increasing frequency in twins and siblings of patient. The aim of the study is to evaluate the clinical presentation, management and outcomes of the patient with congenital inguinal hernia undergoing herniotomy. Methods: This prospective study includes 54 patients who were operated for congenital inguinal hernia at Bundelkhand Medical College and Associated Hospital Sagar from April 2015 to October 2016. Patients of age group 2 months to 12 years were included in the study. Patients presenting with acute scrotal conditions like incarcerated hernia, strangulated hernia and obstructed hernia were excluded from the study. A detailed history, clinical presentation and routine investigations, were done in all cases. Results: In the present study most of the patients were male. Inguinal hernia can occur at any age but majority of the patients $53.70 \%$ are seen between $1-5$ years of age. Swelling in the inguinal region was the commonest symptoms. Incidence is slightly higher on the right side. Almost all of the inguinal hernias in paediatric age group are of indirect type, which develops due to congenitally patent processes vaginalis. The most common post-operative complication was reactive hydrocele and all of them resolved by the second week. No recurrence was reported in the study. Conclusions: Inguinal hernia is a common surgical condition in children. Early surgical intervention in form of inguinal herniotomy is the most appropriate management of inguinal hernia in children
\end{abstract}

Keywords: Inguinal hernia, Herniotomy, Processes vaginalis, Strangulation, Reactive hydrocele

\section{Introduction}

Inguinal hernia in children is quite a common presentation and inguinal herniotomy is a frequently done procedure in children for inguinal hernia. Approximately 400 years ago, a French surgeon named Ambroise Park described the reduction of an incarcerated congenital inguinal hernia and the application of trusses. He recognised that inguinal hernias in children were probably congenital in nature and they could be cured. Unfortunately, despite, the many historical descriptions of conservative medical management of inguinal hernias, no effectivenonsurgical means of treating this condition is recognised. All congenital inguinal hernia requires operative treatment to prevent the development of complications, such as inguinal hernia incarceration or strangulations.

Manuscript Received: $10^{\text {th }}$ March 2018

Reviewed: $18^{\text {th }}$ March 2018

Author Corrected: $24^{\text {th }}$ March 2018

Accepted for Publication: $28^{\text {th }}$ March 2018
Today, inguinal hernia repair is one of the most common paediatric operations performed. Inguinal hernia is a type of ventral hernia that occurs when an intra-abdominal structure, such as bowel or omentum, protrude through a defect in the abdominal wall. Most hernias that are presented on birth or in childhood are indirect inguinal hernia. The processes vaginalis is an out pouching of peritoneum attached to the testicles that trail behind as it descends retroperitoneal into the scrotum.

When obliterations of the processes vaginalis fails to occur, inguinal hernia results [1]. In female the ovaries descend into the pelvis but do not leave the abdominal cavity. The upper portion of the Gubernaculum becomes the ovarian ligament, and lower portions become the round ligament, which travels through the inguinal ring into the labium majus. If the processes 
vaginalis remains patent, it extends into the labium majus and is known as the Canal of Nuck. Before birth, the layers of the processus vaginalis normally fuse, closing off the entrance into the inguinal canal from the abdominal cavity. In some individuals the processus vaginalis remains patent through infancy, into childhood, and possibly even into adulthood. The precise cause of the obliteration of the processus vaginalis is unknown, but some studies indicate that Calcitonin gene related peptide released from the genito-femoral nerve may have a role in the fusion.

The reported incidence of congenital inguinal hernia varies from $0.8-4.4 \%$ [2]. Congenital inguinal hernias are much more common in males with male to female ratio of $3: 1$ and 10:1. Approximately $60 \%$ are seen on right side due to later descent of right testis and delayed obliteration of processus vaginalis. $25 \%$ of the patients have left sided hernia and remaining $15 \%$ had bilateral congenital inguinal hernia [3]. One third of all the children presented to surgical centres with inguinal hernia are younger than 6 months. In preterm babies the incidence is as high as $30 \%$ [4]. Near $40 \%$ of the patients with a clinical unilateral hernia display a patent processus vaginalis on the contra lateral side. But the simple persistence of processus vaginalis is not always ensuring to become symptomatic in future. Congenital inguinal hernia has a higher familiar incidence [5] and it has been observed with increasing frequency in twins and siblings of patients [6]. A number of associated genital disorders including undescended testes, cystic fibrosis, bladder exstrophy, increased intra-abdominal pressure, increased peritoneal fluid and connective tissue disorders may contribute in the presence of an inguinal hernia [7].

An inguinal hernia will not resolve by itself and all cases need surgery. Most hernias in children are indirect these hernias need to be repaired, because they are likely to become incarcerated. Prompt surgery is needed for neonates and infants because risk of incarcerations in these children is more than older one and adults. Hernias those are incarcerated, even after reduction need to be repaired as soon as possible because of risk of strangulations. Surgeries may be delayed as premature babies with hernias that are not incarcerated, because premature neonates at risk of anaesthesia. Traditional technique of surgery (herniotomy) involves the use of a skin crease incision over the groin to dissect out the sac, taking care not to injure the adjacent important structures, namely the vas deferens and testicular vessels. The sac is then divided and proximal end Trans fixed. Some bodies says that in males sometimes the scrotal approach for inguinal hernia or hydrocele repair is a safe procedure without added morbidity and with excellent cosmetic results . Inguinal hernia management by herniotomy is also considered to be the most commonly employed elective surgical procedure in paediatric age group [8, 9]. It is considered to be easy to perform along with a good rate of success and low frequency of complications [10]. However, the introduction of laparoscopy has gained popularity and a variety of laparoscopic techniques for inguinal hernias repair in children have been reported in the literature $[11,12]$. This study is being conducted with the aim to study the clinical presentation and management of congenital inguinal hernia in children.

\section{Materials and Methods}

Study Setting: The study was conducted in unit III Department of Surgery, Bundelkhand Medical College and Associated Hospital, Sagar.

Study Design: The study was a prospective observational study.

Study Period: The study was conducted between April 2015 to October 2016.

Sample Size: This study has included 54 patients.

Inclusion Criteria: All the subjects with age between 2 months and 12 years, belonging to both sexes were included in the study. The study was conducted on the basis of all the patients admitted in ward as elective cases from outpatient department. Patients of age group 2 months to 12 years diagnosed clinically as congenital inguinal hernia and managed by elective herniotomy were included in the study.

Exclusion Criteria: Patients presenting with acute scrotal conditions like incarcerated hernia, strangulated hernia and obstructed hernia were excluded from the study.

Ethical Considerations: The study was approved by the intuitional human ethics committee. Informed written consent was obtained from all study participants. Confidentiality of the study participants was maintained throughout the study.

Study Procedure: All patients underwent through clinical examinations and were evaluated for systemic diseases. All patients were admitted one day prior to surgery. All relevant investigations were done for all the patients including haemoglobin, urine examinations and preoperative anaesthesia evaluation. Nature of hernia 


\section{Original Research Article}

and method of surgery was explained to their parents in their languages. Nil orally 6 hours prior to surgery was advised. Diagnosis was based on history of scrotal swelling, intermittent bulge, swelling on examinations, palpations along inguinal canal, and occasionally it was an incidental finding on ultrasonography. Preoperative xylocaine sensitivity test was done.Written and informed consent of both parents was taken after giving information procedure and possible complications in their own language. Preoperative antibiotics were given half an hour prior to surgery. Anaesthesia used was general anaesthesia, spinal anaesthesia or caudal block.

Patients were taken on table for operation in supine position. Under all aseptic precautions, painting and draping was done. Anterior superior iliac spine and pubic tubercle were marked out. 2 finger breadth upward and laterally skin crease incision was taken approximately $1-1.5 \mathrm{~cm}$. External oblique aponeurosis was identified an incision taken over external oblique aponeurosis and extended medially as well as laterally along the fibres of aponeurosis. Superficial ring was not disturbed al all, two folds of external oblique aponeurosis, cord structure hooked without disturbing neighbouring structures. Longitudinal incision was taken over cremestric tube and opened; pearly white sac was visualized easily on superiomedial aspect of spermatic cord. Sac was identified properly, sac only held and rest of structures reduced inside. Then sac was separated from cord structure without disturbing, pampiniform plexus and testicular vessels. Sac was separated up to deep ring and patency of processus vaginalis was confirmed. Then Trans fixation of the sac as high as possible towards the deep ring, high ligation of sac was done. After high ligation of sac, Ligated stump of retracted into abdominal cavity and haemostasis achieved. One to two sutures were taken over external oblique aponeurosis to approximate opened folds with vicryl 3-0 RB. Skin was closed with subcuticular vicryl 3-0. Dressing was applied. After surgery, all patients transferred to surgery ward. In the postoperative period, patient was kept nil by mouth for at least 4-6 hours.

Early ambulation was done. Most of the patients were discharge on next day of operation. Inspection of surrounding area was done on discharge. Patient reviewed after 3-5 days in OPD. At review, complaints of patients were asked and operative site was examined. Inspection of surrounding area was done and specifically looked for scrotal oedema, seroma formation, wound infection. Stitch removal was done after 8 days or according to status of wound and age. The follow up period in our study rose from three months to one year. No recurrence was reported during this period.

Statistical Analysis: The data was entered into Microsoft excel and analyzed using SPSS version 20 to compute the frequency and percentages.

\section{Results}

A total of 54 patients who presented with congenital inguinal hernia and underwent herniotomy were studied. The study included patients from two months to twelve years of age, which were divided into four categories on the basis of their age: less than 1 year, 1-5 years, 5-10 years and more than 10 years. Maximum incidence was seen in 1-5 year age group $(53.70 \%)$. Youngest patient in this study was 6 months old.

Table-1: Age and Sex Distribution of the patients.

\begin{tabular}{|c|c|c|}
\hline Parameter & No. of patients & Percentage \\
\hline Age (Years) & & 05.55 \\
\hline Less than 1 year & 03 & 53.70 \\
\hline $1-5$ years & 29 & 33.33 \\
\hline 5-10 years & 18 & 7.40 \\
\hline More than 10 years & 04 & 88.88 \\
\hline Gender & & 11.12 \\
\hline Male & 48 & 06 \\
\hline Female & 06 & \\
\hline
\end{tabular}

In our study 48 patients $(88.88 \%)$ were male and 06 patients $(11.12 \%)$ were female thus making a male to female ratio of 7.5:1. A swelling in the inguinal region was the commonest symptom which was presented by the patient attainder 49 patients $(90.74 \%)$ presented with unilateral swelling.5 patients $(9.25 \%)$ did not have any swelling on clinical examination. The swelling in the inguinal region was present for 1-2 year in $90 \%$ of the patients. 
Original Research Article

Table-2: Side of hernia

\begin{tabular}{|c|c|c|}
\hline Side of hernia & No. Of patients & Percentage \\
\hline Right sided & 34 & 62.96 \\
\hline Left Sided & 16 & 29.62 \\
\hline Bilateral & 04 & 7.40 \\
\hline
\end{tabular}

In this study we found that a higher incidence of congenital inguinal hernia on right side $(62.96 \%), 29.62 \%$ hernia left sided and $7.40 \%$ were bilateral congenital inguinal hernia.

Table-3: Associated anomalies.

\begin{tabular}{|c|c|c|}
\hline Associated anomalies & No. Of patients & Percentage \\
\hline Undescended testes & 03 & 5.6 \\
\hline Phimosis & 02 & 3.7 \\
\hline Hypospadias & 00 & 00 \\
\hline Umbilical hernia & 02 & 3.7 \\
\hline Vesical calculus & 00 & 00 \\
\hline
\end{tabular}

The commonest associated anomalies found in our study were undescended testes which were seen in 03 patients (5.6\%). Out of these, in two patients testes were present in the superficial inguinal pouch while in one patient, it was in the inguinal canal. Orchidechopexy was performed in all patients along with inguinal herniotomy. A reducible Umbilical hernia was present with congenital inguinal hernia in two patients $(3.7 \%)$. No surgical intervention was done for it as all of them less than three years of age at the time of surgical repair of inguinal hernia. Two patients (3.7\%) of our study had phimosis, circumcision was performed along with the surgery of inguinal hernia.

Table-4: Contents of sac.

\begin{tabular}{|c|c|c|}
\hline Content & No. Of patients & Percentage \\
\hline Omentum & 38 & 70.37 \\
\hline Bowel (Enterocoel) & 12 & 22.23 \\
\hline Caecum & 01 & 1.85 \\
\hline Ovary/ Fallopian tube & 03 & 5.6 \\
\hline
\end{tabular}

The content of hernia sac in 38 patients (70.37\%) was omentum and next was intestine in 12 patients $(22.23 \%)$. One patient in our study had right sided sliding hernia which was containing caecum in sided. Sliding hernia is uncommon in children. In patient of female content were ovary / fallopian tube in 03 patients $(5.6 \%)$.

Table-5: Postoperative complications.

\begin{tabular}{|c|c|c|}
\hline Complications & No. Of patients & Percentage \\
\hline Reactive hydrocele & 16 & 29.62 \\
\hline Pain & 08 & 14.81 \\
\hline Retention of urine & 06 & 11.12 \\
\hline Wound infection & 03 & 5.6 \\
\hline Recurrence & 00 & 00 \\
\hline
\end{tabular}

Reactive hydrocele is one of the commonest complications in all herniotomy surgeries. According to our study it was noticed in 16 patients $(29.62 \%)$, followed by pain in 08 patients $(14.8 \%)$, retention of urine 06 patients $(11.12 \%)$ and wound infection ) 3 patient $(5.6 \%)$. No recurrence was reported in our study. 


\section{Discussion}

The inguinal hernia is one of the most common surgical conditions in paediatric patients. An Inguinal hernia does not resolve spontaneously and must be repaired because of high risk of strangulation or incarceration [13]. Regarding age distribution approximately $5.55 \%$, $53.70 \% 33.33 \%$ and $7.40 \%$ patients were from less than one year, 1-5 year , 5-10 year and more than 10 years respectively, which shows that the majority of inguinal hernias appear early in life, the fact that should raisetheattention of people, parents, surgeons about this common and easily managed condition. If treated at earlier time i.e. before obstruction, strangulation or incarceration.

Our observations are matching with the observation of Ravi Kumar et al [14] and Jadhav et al [15] who have reported an incidence of $52 \%$ and $44 \%$ respectively in $1-5$ year age group in their study. Okuribido et al [16] have reported an incidence of $47.4 \%$ in children from 37 years of age. In our study 48 patients $(88.88 \%)$ were male and 06 patients $(11.12 \%)$ were female with male to female ratio of 7.5:1. In another studies male to female ratio ranged from 7:1 to 9:1.

It was reported as 7:1 by Grossfeld et al [17] and 9:1 by Poenarau [18]. In this study among 54 patients congenital inguinal hernia accounted for $62.96 \%$ of the hernias on the right side and for $29.62 \%$ on the left side and for $7.40 \%$ that occurred bilaterally. Our observation matched with Jadhav et al and Ravikumar et al who have reported an incidence of $64 \%$ and $56 \%$ for right sided inguinal hernia in their study respectively. Similarly Rowe et al [19] and Grossfeld et al [20] have also reported a higher incidence of inguinal hernia on the right side.

The commonest associated anomaly found in our study was undescended testes, which was seen in 03 patients (5.6\%). Scorer et al [21] found that incidence of undescended testes was $3.4 \%$ which is comparable to our study. In our study 06 female patients with inguinal hernia were additionally studied by USG abdomen to rule out intersex condition. No abnormality was found in any of the female patients. During surgeries, ovary/fallopian tube was found in hernial sac of three female patients. We did not find any case of direct inguinal hernia in our study.

Direct inguinal hernia is rare in paediatric age group and they represent only $0.5 \%$ of all groin hernia [22, 23]. One patient in our study had right sided sliding hernia which was containing caecum inside it. Sliding hernia are uncommon in children, sliding hernia was uniformly treated with as high ligation as possible and then closure of the internal ring. Hernial sac content such as loops of bowel were left alone and pushed back into the peritoneal cavity before routine high ligation of the sac. As regards the complications in our study, reactive hydrocele was noticed in 16 patients $(29.62 \%)$ and all of them resolved by second week.

Hydrocele during postoperative period is a frequent occurrence and indicates the continuing fluid secretion from left over distal sac. More commonly, it occurs as a minor collection which gets reabsorbed on its own, over duration of 2-3 weeks. The occurrence is considered to be more frequent in larger hernias.

It has been suggested that herniotomy procedure should be done taking this into consideration and the distal sac should be laid widely open [24]. Three patients (5.6\%) who developed the complication of wound infection treated with antibiotic. The follow up period in our study ranged from three months to one year. No recurrence was reported during this period. Limitation of our study is that the number of patients and length of follow up is smaller as compare to other studies.

\section{Conclusion}

Inguinal hernias are the common congenital condition in children presented with inguinoscrotal swelling. It is more commonly seen in male children and common on the right side. Though it can develop at any age, even in the neonates but majority of children develop it between the ages of 1-5 years. Almost all of the inguinal hernia in paediatric age group is of indirect type which develops due to congenitally patent processes vaginalis. Once developed, it cannot resolve itself and so early surgical intervention in the form of inguinal herniotomy is the most appropriate management of inguinal hernia in children otherwise it can lead to the complications like obstruction and strangulation.

\section{Contribution from authors}

1. Dr. Nagendra Singh: The objectives and study design were formulated.

2. Dr. Dushyant Kumar Rohit: Contributed to the preparation of the manuscript and data analysis.

3. Dr. Grishm Raj Pandey: Helped in data collection.

4. Dr. R S Verma: Supervised and guided for study. 


\section{Original Research Article}

\section{What this study adds to the existing knowledge?}

This study indicates most of the congenital inguinal hernia occurs in male children and common on the right side. Majority of the children develop it between the ages of 1-5 years which is mostly of indirect type.

Early surgical intervention in the form of inguinal herniotomy is the most appropriate management of inguinal hernia in children.

Acknowledgements-The authors express sincere thanks to Department of Surgery, Bundelkhand Medical College, Sagar, Madhya Pradesh, India for providing the best facilities for the research work.

Conflict of interest: None declared.

Funding: Nil, Permission from IRB: Yes

\section{References}

1. Brandt ML. Paediatric hernias. Surg Clin North AM. 2008 Feb;88(1): p27-43

2. Bronsther B, Abrams MW, Elbiom C. Inguinal hernias in children: a study of 1000 cases and a review of the literature. J Am Med women's Assoc 1972 Oct; 27 (10): p522-525

3. Grosfeld et al, Inguinal hernia in children - The factors which affected the recurrence in 62 cases. Journal of Paediatric surgery.1991 March; Volume 26 Issue 3: p265-87

4. Peevy KJ, Speed FA and Hoff CJ. Epidemiology of inguinal hernia in preterm neonates. Paediatrics 1986 Feb; 77(2): p246-247

5. Czeizel A, Gardonyi $\mathrm{J}$ et al. A family study of congenital inguinal hernias. American Journal of Medical Genetics 1979; Volume 4 Issue 3: p247254.

6. Jones ME, Swerdlow AJ, Griffith M, Goldacre MJ. Risk ofcongenitalinguinal hernia in siblings: a record linkage study. Paediatr Perinat Epidemiol.1998 Jul; 12 (3): 288-96.

7. Glick LP, Boulanger SC et al. Inguinal hernias and hydrocele. Paediatric Surgery Sixth Edition Volume 2 Mosby 2006: p1172-1192.

8. Kapur P Caty MG, Glick PL. Paediatric hernias and hydrocele. Paediatric Clin North AM 1998 Aug; 45(4): p773-85.
9. Nazem M, Heydari Dastgerdy MM, Sirousfard M. Outcomes of Paediatric Inguinal hernia repair with or without opening the external oblique muscle fascia $\mathrm{J}$ Res Med Sci 2015 Dec; 20(12): p1172-1176

10. Saranga Bharathi R, Arora M, Baskaran V. Paediatric inguinal hernia: Laproscopic vs Open surgeries. JSLS, 2008 July- Sep; Volume 12 (3): p277-281.

11. Yip KF, Tam PK and Li MK. Laparoscopic flap hernioplasty: An innovative technique for Paediatric hernia surgery. Surgical Endoscopy 2004 July; Volume 18 Issue 7: p1126-1129

12. Saka R, Okuyama H. Sasaki $T$ et al. safely and efficiency of laparoscopic percutaneous Extra peritoneal Closure for inguinal hernia and hydrocele in children. A comparision with traditional open repair. Journal of Laproendoscopic Advanced Surgical technique Part A 2014 Jan; Volume 24 Issue 1: p55-58

13. Suvera MS, Damor PB Patel SB. Surgery for Inguinal hernia in Paediatric age. Int $\mathrm{J}$ Res Med Sci 2013 May;Volume 1Issue 2: p112-115

14. V Ravikumar, Rajshankar S, Haresh R. S. Kumar, Nagendra Gowda MR: A clinical study of management of inguinal hernias in children on the general surgical practice. Journal of Clinical and Diagnostic Research 2013 January; Volume 7 Issue 1: p144-147

15. Dinesh L Jadhav, Manjunath L, Vikas G Krishnamurty: A study of inguinal hernia in children. Int J of Science and Research, Dec 2014, Volume 3 (12): $\mathrm{p} 2149-2155$

16. Okunribido O, Ladipo JK and Ajao OG. Inguinal hernia in paediatric age group, Ibardan experience, East Afr. Med. J, 1992;Volume 69 Issue 6: p347-348

17. Grosfeld JL. The current concepts in inguinal hernias in infants and children. World Journal of Surgery 1989 Sep- Oct; Volume 13 Issue 5: p506-15

18. Dan Poenaru, Inguinal hernias and hydrocele in infancy and child hood: A consensus statement of the Canadian Association of Paediatric Surgeons: Paediatric Child Health,2000Nov-Dec;Volume5 Issue8: p461-462.

19. Rowe MI, Copelson LW, Clatworthy HW. The patent processus vaginalis and the inguinal hernia. $\mathrm{J}$ Pediatr Surg. 1969 Feb;4(1):102-7. 
20. Grosfeld et al. Inguinal hernia in children, the factors which affected the recurrence in 62 cases. Journal of Paediatric Surgery 1991 March: Volume 26 Issue 3: p265-83.

21. Scorer CG, Farrigton GH. Congenital deformities of testes and epididymis. London Butterworth's: 1971; Chapter 3: p15-102.

22. Rescorla FJ, Grosfeld JL. Inguinal hernia repair in the perinatal period and early infancy: clinical considerations. J Pediatr Surg. 1984 Dec;19(6):832-7.
23. Holder TM, Ashcraft KW. Groin hernias and hydroceles. Paediatric Surgery Edition 1: Philadelphia WB Saunders Company 1980; p594-608.

24. Gahukamble DB, Khamage AS. Prospective Ramdomized controlled study of excision vs distal splitting of hernia sac and processus vaginalis in the repair of inguinal hernias and communicating hydrocele. J Paediatric Surg. 1995 April; Volume 30 Issue 4: p624-5.

\section{How to cite this article?}

Singh N, Rohit D. K, Verma R.S, Pandey G. Clinical study and management of congenital inguinal hernia in a tertiary care teaching institute. Surgical Update: Int J surg Orthopedics.2018;4(1):52-58.doi:10.17511/ijoso.2018.i01.09. 